\title{
Obtaining a Foundation for Nursing Care at the Time of Patient Admission: A Grounded Theory Study
}

\author{
Inger Jansson $^{*}, 1,2$, Ewa Pilhammar ${ }^{2}$ and Anna Forsberg ${ }^{2}$ \\ ${ }^{1}$ School of Social and Health Sciences, Halmstad University, Halmstad, Sweden \\ ${ }^{2}$ The Sahlgrenska Academy at Göteborg University, Institute of Health and Care Sciences, Sweden
}

\begin{abstract}
The nursing process can be viewed as a problem-solving model, but we do not know whether use of the whole process including care plans with interventions based on nursing diagnoses improves nurses' ability to carry out assessments. Therefore, the aim of this study was to illuminate and describe the assessment and decision-making process performed by nurses who formulated individual care plans including nursing diagnosis, goals and interventions or who used standardized care plans when a patient was admitted to their ward for care, and those who did not. Data collection and analysis were carried out by means of Grounded theory. Nurses were observed while assessing patients, after which they were interviewed. The main concern of all nurses was to obtain a foundation for nursing care based on four strategies; building pre-understanding, creating a caring environment, collecting information on symptoms and signs and performing an analysis from different perspectives. It appeared that the most important aspect for nurses who did not employ care plans was the medical reason for the patient's admission. The nurses who employed care plans discussed their decisions in terms of nursing problems, needs and risks. The results indicate that nurses who formulated care plans were more aware of their professional role.
\end{abstract}

Keywords: Nursing process, assessment, judgment, decision-making process, critical thinking.

\section{INTRODUCTION}

Assessment of the patient's care needs based on his/her perception of the illness is essential for the provision of high quality nursing care, as it provides information about the complexity of the patient's health situation. Nursing diagnoses, which is the result of assessment, is seldom used in Swedish clinical care settings $[1,2]$ and there is a problematic gap between guidelines and teaching about the topic in nursing education programs and how it is used in everyday work [3].

\section{KEY CONCEPTS}

Assessment is the first phase of the nursing process [4] and includes nursing history, health assessment and nursing diagnosis. According to Thomas and Coombs [5], a nursing diagnosis can be defined as a statement of conclusion resulting from recognition of the pattern derived from a nursing investigation of the patient. Nursing diagnosis has also been defined by North American Nursing Diagnosis Association (NANDA) as "a clinical judgement about an individual, a family or a community's responses to actual and potential health problems/life processes. Nursing diagnoses provide the basis for selection of nursing interventions to achieve outcomes for which the nurse is accountable" [6, p. 219]. In this study, the concept of assessment is defined as an evaluation of the nature and extent of nursing problems presented by a patient for the purpose of patient care planning. Assessment is aimed at identifying nursing problems.

*Address correspondence to this author at the School of Social and Health Sciences, Halmstad University, P.O. Box 823, SE-301 18 Halmstad, Sweden; E-mail: Inger.Jansson@hh.se
The concepts of decision-making and judgement concern critical evaluation performed by the nurse and are described as the process of making a selective intellectual judgment when presented with several complex alternatives consisting of a range of variables, i.e. nursing problems presented by the patient, as well as definition of a course of action or an idea, i.e. a nursing care plan. Finally, in this study the concept of critical thinking involves all steps of the nursing process.

\section{STATE OF THE ART}

According to Fesler-Birch [7], the nursing process is a useful tool that provides the nurse with a problem-solving model that can serve as a framework for critical thinking, as each of its components corresponds to a scientific method.

State of the art in this area has been well documented in a systematic review by Muller-Staub et al. [8]. This review comprised totally 37 articles and 14 studies focused on the effects of nursing diagnosis. All 14 studies reported qualitative improvements in the assessment of nursing care problems. Eight studies revealed coherence between nursing diagnosis, interventions and outcomes, while, in 10 studies, the frequency of nursing diagnosis documentation varied between sites and clinical settings. Four studies employed an ongoing educational intervention and found statistically significant improvements in the documentation of diagnosis, interventions and outcome. Limitations in diagnostic accuracy, reporting of signs/symptoms and aetiology were reported in all 14 studies. In a more recent study by MullerStaub et al. [9] it was stated that an educational intervention using a case discussion method in the implementation of nursing diagnoses and interventions based on the NANDA, Nursing Intervention Classification (NIC) and Nursing 
Outcome Classification (NOC) led to higher quality nursing diagnosis, documentation, aetiology specific nursing interventions and nursing-sensitive patient outcomes. An intervention with guided clinical reasoning [10] also resulted in higher quality nursing diagnosis documentation, aetiology specific interventions and enhanced nursing-sensitive patient outcomes. After the implementation of standardized language involving planned work in groups as well as education and support, a significant improvement was found in the assessment, diagnosis and intervention steps in the nursing process [11]. In a Cochrane report [12] that included nine trials aimed at assessing the effects of nursing record systems on nursing practice and patient outcome, the authors found limited evidence that changes in record systems affected practice and recommended more qualitative nursing research to explore the relationship between practice and information use. According to Ehrenberg and Ehnfors [13], nurses lack the skill to correctly assess patient care needs. Björvell et al. [14] stated that the assessment part of the nursing process requires critical thinking and reflection, which is both time consuming and complex. Studies of assessments revealed that nurses and patients disagreed in their perceptions of the presence, severity and significance of health problems $[15,16]$ and that there were a number of instruments available for improving assessment, but which were rarely used [17].

In a review, Tanner [18] demonstrated that clinical judgement was influenced by the nurses' background, the context of the situation and their relationship with the patients. In their respective reviews, neither Banning [19] nor Lee et al. [20] found any conclusive evidence of the distinctive process in which nurses engage when diagnosing the clinical condition of patients. Lunney [21] distributed data from the same patient to 80 experienced nurses, based on which the nurses arrived at 46 different interpretations, thus indicating that the thought process is probably far more complex than is generally realized. According to Lunney [22], the provision of high quality nursing care requires the use of critical thinking in three areas: nursing diagnoses, health outcomes and nursing interventions. In order to improve their ability, nurses need knowledge of these topics as well as opportunities for practice. This can be achieved by the use of case studies, but the limitations are that they do not represent all aspects of reality.

Banning [19] described three clinical decision making models: (1) the information-processing model that uses a scientific hypothetic-deductive, quantitative approach, (2) the intuitive-humanistic model that focuses on intuition and how the knowledge gained from nursing experience enriches the clinical decision making process and (3) the clinicaldecision model that uses both hypothetico-deductive and pattern recognition. Lee et al. [20] stated that the real-world situation in the process still remains largely unexplored. In our literature review, we only found one study that focused on the first assessment of caring needs in a real-world situation when a patient is admitted to a ward. It was performed by means of observations of and interviews with nurses [23] and revealed that observing the patient's verbal and non-verbal language was the most common method of acquiring information about his/her health status. Other methods of assessment were talking to, watching and examining the patient as well as reading his/her medical record. In Sweden, nurses use the evidence based VIPSmodel to document nursing in the patient records but they often exclude nursing diagnosis. VIPS, which is defined as Well-being, Integrity, Prevention and Safety, corresponds to the different parts of the nursing process. Its aim is to contribute to structured documentation by means of "keywords" [24]. In the nursing assessment part, the keywords are similar to "the functional health patterns" by Gordon [25], which should be used to standardize the nursing assessment format. In Sweden, the training method for the use of nursing diagnoses is based on Carnevali's Problem Etiology Symptom (PES)-structure [26], where the nurse writes the diagnosis without employing standardised terms. In conclusion, there is a lack of data from real time observations of the state of the art in this area to explain how nurses perform their assessment of patients on admission to hospital and their reason for stating or not stating nursing diagnoses. Therefore, the aim of this study was to illuminate and describe the assessment and decision-making process performed by nurses who formulated individual care plans including nursing diagnosis, goals and interventions or who used standardised care plans when a patient was admitted to their ward for care, and those who did not.

\section{METHODS}

Data collection and analysis were performed using Grounded Theory (GT), which is an inductive research method, suitable for the study of social processes. The method was first described by Glaser and Strauss [27] and later modified by the inclusion of new ideas in the area in which it exists [28]. The aim of the GT method is theorizing, which implies the development of concepts as well as specifying the relationship between them [29]. The developing theory should be based exclusively on the data and not forced to fit into an already existing theoretical framework [30]. The present study was guided by the so called "classic grounded theory" [27] but was also influenced by the constructivist mode of grounded theory which, according to Charmaz [31], differs from "objectivist grounded theory". Constructivism builds on a tradition of interpretative social research, while classic grounded theory is based on a more positivistic approach [32]. The interpretation of constructivistic GT is that scientific data and values are inter-linked and that data and analysis are social constructions and therefore cannot be regarded as objective facts [32].

\section{Study Group}

Although it does not fully accord with the GT method, strategic sampling was performed in order to obtain a broad perspective on patient assessment. The study group comprised 19 nurses from three hospitals in the west of Sweden representing different levels of care in both university and regional hospitals. Nine of the nurses worked on hospital wards that did not employ nursing diagnoses or care plans which means that in spite of Swedish legislation, they did not formulate individual care plans comprising nursing diagnosis, goals and nursing interventions. Nor did they use standardized care plans. These nurses were chosen from units specialising in medicine, surgery and rehabilitation and had a mean work experience of 11 years (range 2.5 - 25 years). The other ten nurses worked in 
hospital wards where nursing diagnoses and both standardised and individual care plans were part of the daily routine. These nurses were selected from units specialising in medicine, infection, surgery and rehabilitation and had a mean work experience of 11 years (range $4-25$ years). The unit leader on each ward assisted in the recruitment of participants for the study with no instructions other than to adhere to the inclusion criterion, which was a minimum of two years' work experience as a registered nurse. According to Benner [33], such nurses can be regarded as competent. All informants participated voluntarily. Verbal informed consent was obtained from both nurses and patients and they were made aware of their right to withdraw at any time.

\section{Data Collection}

After approval by the Regional Ethics Committee in Göteborg (Reg. no. 583-05), the data collection was performed in two steps; observation and interviews. During step one, nurses were observed while assessing patients' health problems and care needs with focus on their choice of setting for the admission interview, how they established an interpersonal relationship with the patient and the strategies they employed for assessing and making decisions pertaining to the patient's care needs. The patient assessment took place during the admission interview, which was the only assessment phase observed by the researcher. The duration of the assessment/admission interviews varied between 15 and 30 minutes. The next step took place immediately after the observation and consisted of open ended research interviews focusing on the nurses' thoughts about the assessment and the decisions made. Each interview lasted 30-45 minutes and confidentiality was assured. The interviews began with an open question "Can you please describe what took place during the assessment?" in order to construct the data in consultation with the participants. This involved posing questions related to issues that arose from the content of the observations, for example, "what were you thoughts when...why?" Additional questions were posed in order to probe the respondent's answers. An interview guide and open sampling were used. As data collection and analysis were conducted simultaneously, the early analytic work led to new questions about the emerging themes, and theoretical sampling was introduced in order to complement the previously captured knowledge and reach theoretical saturation [30]. The data collection continued until saturation was reached, i.e. when no new data emerged [31]. Notes were made during the observations and the interviews were audio-taped and transcribed verbatim. The data collection took place during 2006-2007.

\section{Data Analysis}

Two of the researchers (IJ and AF) read and coded the material. The data were examined line by line. Open coding was performed and substantive codes created, a number of which made analytic sense. Focused coding was then applied to all data. As the data collection and analysis were performed simultaneously, new codes continued to emerge, which created a need to return to earlier data or some respondents in order to further explore an event or issue. Categories that had overriding significance in explicating events or processes were created by means of focused coding, and subcategories developed. Continuous comparison of similarities and differences between all subcategories and categories was carried out in the form of memo-writing [31]. Finally, a core category was identified, illuminating the nurses' main concern when assessing patients' needs in the course of an admission interview. The core category can be related to all other categories and subcategories.

\section{FINDINGS}

A core category, "Obtaining a foundation for nursing care", was identified and illuminates the main concern of all the participants when they encountered the patient at the time of admission. The core category was related to all four categories and involved all of the participants. It described the steps in the information seeking process on which the decision about nursing care needs was based, i.e. "building pre-understanding", "creating a caring environment", "collecting information on symptoms and signs" and "analysis from different perspectives". Each category was divided into sub-categories, the content of which differed in some areas between nurses who employed or did not employ nursing diagnoses and care plans, as can be seen in Fig. (1). In the text, the subcategories are presented in italics.

\section{Building Pre-Understanding}

In the first category, labelled "building preunderstanding", the nurses gathered information before they met the patient. If the patient was transferred from the emergency department, the ward nurse received an oral report from a colleague in that department. The nurse also read the medical record from which he/she collected information about the reason for admission as well as the medical anamnesis. In addition, X-ray, laboratory and other test results were gathered, if available. In this phase, the data collection carried out by the nurses who did not formulate nursing diagnoses or employ written care plans only concerned objective findings or biomedical markers and they exhibited no interest in reading previous nursing records. Nor did these nurses collect information from other nurses who were familiar with the patient.

"And I always want to be prepared for what's
coming/ land check whether the doctor has
made a notel land perhaps the X-ray results as
well/ II can see what the patient's blood
pressure, pulse rate and temperature have been
and whether an ECG was performed, thus
obtaining a picture of how ill the patient is."

In addition to the medical reasons, nurses who stated nursing diagnoses and employed written care plans studied nursing documentation such as discharge notes and home nursing details, as they considered it a valuable source that enabled them to gain an overall impression of the patient. With reference to the discharge notes, one of these nurses commented:

$$
\begin{aligned}
& \text { "It's very helpful to have such information. } \\
& \text { Especially as so many of them have cognitive } \\
& \text { problems. Some are afflicted by aphasia..." }
\end{aligned}
$$

\section{Creating a Caring Environment}

In the second category, labelled "creating a caring environment", the nurses were aware of the importance of 


\section{\begin{tabular}{c|c} 
Core \\
category:
\end{tabular} Obtaining a foundation for nursing care}

\begin{tabular}{|c|c|c|c|c|}
\hline Process: & & $\begin{array}{c}\text { Creating a caring } \\
\text { environment }\end{array}$ & Collecting information & Analysis from different \\
\hline & $\begin{array}{l}\begin{array}{l}\text { Builaing } \\
\text { pre-understanding }\end{array} \\
\text { All nurses: } \\
\text {-oral report } \\
\text {-medical record } \\
\text {-test results } \\
\\
\text { Nurses employing } \\
\text { care plans: } \\
\text {-nursing - } \\
\text { documentation }\end{array}$ & $\begin{array}{c}\begin{array}{c}\text { All nurses: } \\
\text { insight that the caring } \\
\text { relationship is } \\
\text { asymmetric }\end{array} \\
\begin{array}{c}\text { Nurses not employing } \\
\text { care plans: }\end{array} \\
\text {-Allow themselves } \\
\text { to be disturbed } \\
\text { Nurses employing } \\
\text { care plans: } \\
\text { Do not allow themselves } \\
\text { to be disturbed }\end{array}$ & 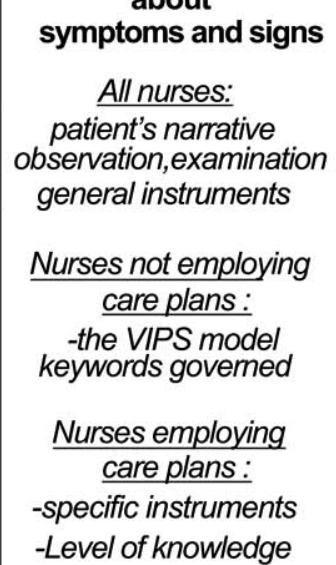 & $\begin{array}{c}\text { perspectives } \\
\text { Nurses not employing } \\
\text { care plans: } \\
\text {-medical reason } \\
\text {-need of primary healthcare } \\
\text {-paramedical contacts } \\
\text {-decisions about } \\
\text { immediate nursing } \\
\text { interventions } \\
\text { Nurses employing } \\
\text { care plans: } \\
\text { decisions about } \\
\text { nursing problems, } \\
\text { needs and risks }\end{array}$ \\
\hline
\end{tabular}

Fig. (1). The assessment and decision-making process performed by nurses at the time of patient admission to a somatic ward.

building a good relationship with the patient during the admission interview. All the participants demonstrated the insight that the caring relationship is asymmetric. They were aware of the fact that the patient is always in a position of dependence and thereby at a disadvantage in relation to the staff, thus they tried to find a form of encounter that minimised the asymmetry. During the admission interview, all nurses ensured that the patient was sitting as comfortably as possible and several of them stressed the importance of being physically on the same level as the patient.

\footnotetext{
"One should try to physically lower oneself to his/her seating level ..."
}

Nurses who did not employ written care plans often conducted the interview in the patient's room, where they were disturbed by doctors, colleagues and fellow patients. They did not try to prevent interruptions, as, in their view, they did not affect the interview to any great extent.

\begin{abstract}
"Actually, one should perhaps have a bit more privacy but it's difficult to arrange...//As a matter of fact I think that most patients don't mind that there are other patients present ..."
\end{abstract}

Despite the fact that the nurses chose not to conduct the interview in private and more or less accepted interruptions during the assessment, they made efforts to build a relationship that enabled them to obtain subjective information about the patient's well-being. For most of the nurses who employed care plans, not being disturbed during the admission interview was a matter of course. For example, during one interview conducted by a nurse who considered that privacy was a necessary condition for interviewing, a doctor entered the room but immediately excused himself and left when he realized that there was an interview in progress. This attitude seemed most common among nurses whose intention was to formulate individual nursing diagnoses.

\section{Collecting Information About Symptoms and Signs}

All nurses listened to the patients' narratives during the admission interviews and, in addition, employed observation and examination to identify signs. Observations were described by the nurses as "their clinical eye", "their intuition" or other similarly vague terms, while examinations were generally more specific and concrete. However, both observations and examinations were guided by the nurses' professional knowledge, previous clinical experience and tacit knowledge.
"Yes, you can see whether people feel well or not. She looked fairly alert and cheerful, despite having quite a lot of complaints. She talked a great deal while others can be more introvert and appear sadder". (Observation)
"I look at their appearance and skin colour and whether they are hot, cold or in a cold sweat, and as stroke is frequently involved, I look for pareses, weaknesses, speech difficulties, whether they appear not to understand, see or hear, so you check on all those things simultaneously." (Examination)

General instruments were used by all nurses for the purpose of measuring pulse rate, blood pressure, oxygen saturation, breathing rate, telemetry and temperature. Nursing specific instruments comprised: Minimal nutrition assessment (MNA) [34], Body Mass Index (BMI) [35], Swallowing Assessment Scale (SSA) [36], Activities of Daily Living (Katz' ADL-index) [37], Risk of pressure ulcers (The Norton Scale) [38], Pain measurement by means of the Visual Analogue Scale (VAS) [39] and Risk of fall injuries [40] and were employed to varying degrees by the 
nurses who aimed to formulate nursing diagnoses and write care plans. These nurses also wished to assess the patient's level of knowledge, for example whether he/she knew what had happened in the acute situation or how much information he/she had assimilated:

"In this case it's mostly how much she knows
about why she is here, she's here to undergo an
assessment due to changes, and what she has
been told. The words the doctor used when
talking to her give you an idea about her
position."

The participating nurses employed the VIPS-model [24] search words from the sections dealing with nursing history and nursing status, as these concerned the information they wished to obtain. During the interview, most of the nurses who did not employ written care plans consulted a template comprising the search words to ensure that they did not omit anything. In spite of the fact that the search words included physical, psychological, social, cultural and spiritual areas, the focus was on how the patient managed at home and whether or not he/she is in receipt of assistance from the home-help service or district nurse. Questions regarding nursing status primarily dealt with physical complaints and care needs. These nurses made a conscious decision not to concentrate on the whole and not to enquire about spiritual/cultural and sexual areas.

\begin{abstract}
"for instance I almost always skip the questions on sexuality, because they are not really related to the care we provide. I think that these questions are more relevant to the gynaecological department. I often skip the spiritual/cultural questions but it can happen that you have to ask them due to the patient being a member of a certain religion although I usually skip them ..."
\end{abstract}

\section{Analysis from Different Perspectives}

The patient's health problems and care needs were analyzed from different perspectives by the nurses and divided into five subcategories: "Medical reasons", "paramedical contacts", "decisions about immediate nursing interventions", "need of primary healthcare" and "decisions about nursing problems, needs and risks".

In the overall assessment, the most important information for the nurses who did not employ written care plans was the medical reason for the patient's admission to the ward.

\footnotetext{
"The reason she came to this department was cardiac fibrillation. That's what we are supposed to deal with here".
}

The nurse carried out the doctor's medical orders, such as the administration of medication and taking samples, in order to quickly arrive at a medical diagnosis.

\footnotetext{
"so now I will phone the doctor and discuss whether I should give him (the patient) more xxxx and I will fetch the medical record and check if he has previously undergone an ECG, after which we will continue with cardiac tests and monitor him."
}

With reference to the patient's need of primary healthcare, the nurse also wanted to plan the social aspects to ensure that everything was in place when he/she was ready for discharge.
"....then it's up to the doctors to assess whether we should continue, otherwise we have to look at her home situation, if she can manage on her own at home, how we should deal with that situation."

The nurses recognized the need for paramedical contacts that allowed them to hand over the assessment of different areas to other professionals with specific competence.

$$
\begin{aligned}
& \text { "I can call in an occupational therapist and a } \\
& \text { speech therapist to make cognitive } \\
& \text { assessments..." }
\end{aligned}
$$

The nurses also made decisions about immediate nursing interventions. This concerned the patient's need for assistance such as help to go to the toilet and managing bowels and bladder, lying position, clothing, shower, meals and ensuring that he/she received the right type of diet and that any ulcers that needed redressing were taken care of.

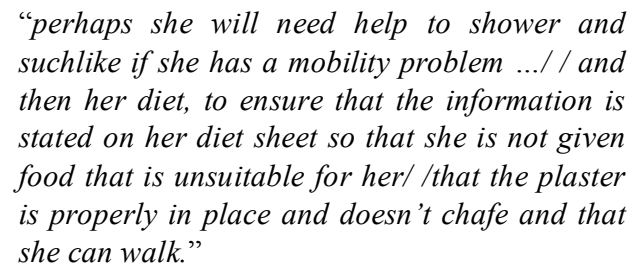

These decisions were not always made on the basis of the patient's narratives about subjectively experienced problems and needs. Our observations revealed lack of acknowledgement of the need for food, as a patient was not offered a meal despite having had nothing to eat since 7 o'clock in the morning (the interview took place at 4 o'clock in the afternoon). Another example of lack of awareness of the patient's needs was an observation where the patient's subjective description and interpretation of her chest pain was ignored, as there were no objective findings or markers that indicated vascular spasm:

\begin{abstract}
"Of course chest pain and things like that in women are always tricky. They are unclear in the case of myocardial infarction, but in this case I felt that the indications were definitely on the psychological level so to speak."
\end{abstract}

The nurses who intended to formulate nursing diagnoses and written care plans used a different strategy. They discussed in terms of decisions about nursing problems, needs and risks. These nurses seemed to have a nursing specific and patient-centered perspective, which included comparing the patient's description of his/her symptoms with more objective findings in the form of blood test results and various measurements in order to verify and strengthen the analysis of the patient's health problems. One nurse expressed the following about a patient who felt tired:

\footnotetext{
"If the patient comes from the emergency ward it's sometimes possible to find an explanation in the test reports, high CRP or low $\mathrm{Hb}$ or something else, whether they have had too much
} 
carbon dioxide as a result of receiving oxygen ..."

There were also cases when the nurse's analysis did not seem to match the patient's experiences:

\begin{abstract}
"While on the one hand you should go by his feeling that he is quite ok, on the other it may be due to the fact that something else is malfunctioning. He was admitted with suspected stroke and a stroke could cause him not to experience himself as poorly, so in this case you have to take account of the fact that he is dizzy and drowsy, which indicates that there is something seriously wrong because not everybody suffers from such symptoms, and the fact that he falls asleep while talking is not a good sign, thus it doesn't matter how well he feels, he is obviously ill!"
\end{abstract}

These nurses intended to formulate nursing diagnoses and write individual care plans for the patients. Such methodology demands nursing specific critical thinking and their competence seemed to vary from basic to advanced, mainly due to personal experience. In units that only used standardized care plans based on medical diagnoses or treatment without individual care planning, little critical thinking took place during the observation and interview. When engaging in a basic level of critical thinking, the nurses attributed the same weight to all nursing problems. Moreover, "related factors" and possible associated problems were discussed rarely or not at all. However, an advanced form of critical thinking about the interrelationship between problems was also exhibited by nurses with long experience of individualized care planning, which is illustrated by the following quotations:
"It's more or less down to which measures I decide upon for the patient and it may be that the diagnosis turns out to comprise not only one but two problems that you then have to incorporate."
"Let's say that the patient is admitted and has vomited several times at home and says that he/she feels very sick and can't keep anything down and ... then you ask how many times he/she has vomited and what it looks like and so on and then I want to know how the attacks come on because of the balance in their body and what their urine looks like, its volume and so on, if they need drip-feeding for example. I need to know because of the risk of dehydration."

Overall, nurses who formulated nursing diagnoses and care plans considered the patient's experience to be of paramount importance and planned the nursing care around that which the patient regarded as problems or needs. Risk diagnosis was established in two ways; partly with reference to the examinations and measurements made by the nurse, often using a nursing specific instrument, and partly on the basis of previous nursing diagnoses in standardized care plans. These nurses discussed whether or not the nursing diagnoses in the standardized care plan corresponded with the patient's condition and needs.

\begin{abstract}
"I consider the patient as a whole, what the problem is, why the patient has sought help, and then I make a diagnosis and formulate a goal based on the diagnosis, after which I carry out my nursing interventions."
\end{abstract}

The nursing diagnosis mainly focused on difficulties related to nutrition, respiration, circulation, activity level and pain. Lack of knowledge/information was a common problem, as was the patient's home situation and social planning.
"breathing, nutrition and appetite, these are the sort of things that you need to include in the care plan and see to it that the patients receive the nursing care they require."
".....Yes, the doctor concentrates more on medical aspects, however, this is nursing care and includes information, examination, food, diet, pain, things like that"
"then you have to focus on social planning and see to it that she returns to her home environment... where I assume her quality of life is best"

Whether or not the nurses' intention was to formulate a nursing diagnosis, the focus was on physical and social areas.

\section{DISCUSSION}

\section{Methodological Considerations}

Charmaz [31] described four criteria for grounded theory studies: credibility, originality, resonance and usefulness. We strived to achieve credibility by means of the authors' mutual reflection during the analysis and discussions about various ways of interpreting the results, as well as by presenting quotations that enable the reader to judge the credibility of our interpretation. Additionally, we collected data until saturation, which means that data collection continued until no new data emerged. Nineteen assessments were made where 19 nurses were observed, after which they were interviewed. Observations always carry the risk of capturing "one moment in time" where the person being observed makes a greater effort than usual and takes a different approach towards the patients. In this study each nurse had vast experience of carrying out assessments, and the researcher performing the observations gained the impression that the participants performed the admission interviews in their usual way. In grounded theory, the amount of data about different processes is of interest and in this case the total data encompassed far more than the 19 assessments observed. The originality of the present work is that it indicates differences between nurses who employed nursing diagnoses and care plans and nurses who did not, which to our knowledge has not been described previously. The resonance of the present work is that it reveals that nurses who work with nursing diagnoses and care plans seem to have a different view of their professional role than their colleagues who do not work in that way. Usefulness is demonstrated by the fact that the result can serve to make 
nurses more interested in further evaluation of the use of nursing diagnoses and care plans.

\section{Discussion of the Results}

The main concern of all the nurses in the admission interview with the patient was to obtain a foundation for nursing care. This foundation was based on four steps; building pre-understanding, creating a caring environment, collecting information on symptoms and signs and, finally, performing an analysis from different perspectives. The decision-making process at this point might seem to be linear. However, this is just a description of the process that took place when the patients were admitted to the ward. We did not study the nurse-patient interaction during the patient's hospital stay, but it can be assumed that the nurse shifted between the steps in the assessment process.

The aim of all nurses was to provide good care, but in the analysis of the assessed information their perspectives differed. The results of this study indicate that nurses who formulated nursing diagnoses and care plans were more aware of their professional role, as they used a nursing perspective. Nurses who had no intention of formulating nursing diagnoses and care plans seemed to have a more medically oriented perspective in their assessment.

All nurses began their assessment by acquiring preunderstanding. The strategy of nurses with a medical perspective was to only read the medical records and objective test results. Nurses with a nursing perspective considered the nursing record an important source of information, although they also studied the medical reasons for the patient's admission in order to gain an overview of his/her health status.

Nursing theories imply a perspective on the human being, where the nurse respects the patient's integrity, autonomy and dignity as well as listening to his/her account and experiences. The nurses in the present study considered it a matter of course to conduct an admission interview with the patient and listen to his/her narrative when he/she arrived on the ward. This is in line with Fredriksson and Eriksson's [41] description of "the caring conversation", which means "a conversation between a patient and a nurse in which the patient can carve out his or her narrative of suffering" ( $p$. 139). It was obvious to some nurses that the admission interview should be planned in terms of time and that all forms of interruption should be avoided. This was most common among the nurses who intended to formulate nursing diagnoses and indicates that they considered the meeting important for their interpretation of the patient's needs. Other nurses allowed themselves to be interrupted, indicating that the caring conversation was not prioritised.

The admission interviews provided the nurses with information about the patient's symptoms. However, they also assessed signs in order to obtain a complete picture. According to the Encyclopaedia Britannica [42], the difference between symptoms and signs is:

\footnotetext{
"a sign is defined as an objective manifestation of disease that can be determined by a physician: a symptom is subjective evidence of a disease reported by the patient".
}

The nurses assessed signs by means of general observation of the patient's body based on their physiological knowledge, which they then considered in relation to the patient's narrative and the doctor's medical diagnosis. They also took account of biomedical markers and employed general measurement instruments to establish the reason for the patient's symptoms. In addition, certain specific measurement instruments were used by nurses who intended to employ nursing diagnoses and written care plans, as they formed part of a norm that governed the use of a specific standardised care plan. This was not applicable to nurses who had no intention of formulating nursing diagnoses or care plans. A study by Ehrenberg and Ehnfors [13] revealed that instruments that can enhance assessment are rarely used. All nurses looked for signs in order to identify or verify the reason for the problems described by the patient, but they attributed different significance to them, depending on their decision-making perspective. According to the VIPS model [24], referred to by some nurses, the nurse should be able to obtain a complete picture of the patient's health problems, care needs, preferences and abilities. However, in reality this was not the case. Instead, the nurses used the search words they considered important, which resulted in an assessment based on areas deemed essential by the nurse instead of starting from the patient's own narrative and nursing history. The nurses who did not refer to the VIPS-model search words only used them for documentation, which may give the patient an opportunity to relate what is important to him/her.

Nursing is a broad concept and even nurses have great difficulty defining it. In order for nurses to make a nursing diagnosis, they must become familiar with that which constitutes the profession's area of responsibility as well as obtain knowledge of critical thinking and reflection. According to Björvell et al. [14], lack of these prerequisites prevents many nurses from making a diagnosis. Orlando holds that it is necessary to teach the nursing process in nursing education in order to ensure that nurses are capable of providing high quality care [43]. Learning to think critically is a difficult process, which, according to Pesut [44], requires a framework for each specific discipline that gives meaning to a set of facts. Nurses frame issues in terms of patients' responses to questions regarding health status and situations, which can be compared to physicians who focus on disease and pathophysiology [44].

For the nurses in the present study who did not formulate nursing diagnoses, the most frequently observed cues were related to biomedical rather than specific nursing knowledge, which has also been described by Hedberg et al. [23]. Hancock et al. [15] revealed that nurses perceived the most important aspects of nursing to be implementing, observing and reporting as well as carrying out the doctor's orders. We argue that the framework, which, according to Pesut [44], is specific to the nursing discipline, was not obvious to the nurses in the present study who did not formulate nursing diagnoses. In our opinion, the strategy used by these nurses was similar to the information-processing model [19], which is grounded in medical decision making and is hypotheticdeductive and inspired by a quantitative approach. The nurses who were not familiar with their own professional area only looked for signs that supported the hypothetical reason for admission, i.e. myocardial infarction. They also 
found it difficult to explain certain concepts such as "intuition" despite having used the term themselves. The concept of intuition is often referred to in the literature [e.g. 45] in relation to "expert" nurses and employed in the intuitive-humanist decision-making model [19]. However, in our opinion, these nurses did not use this approach, which, according to Benner \& Benner [45], can be obstructed by personal learning strategies and interests as well as barriers in the organization in which the nurse is employed.

The nurses who made nursing diagnoses used a different strategy in their critical thinking. As they utilized all parts of the nursing process, they were also familiar with their professional area. This is supported by Axelson's [46] study, in which nurses reported that making nursing diagnoses had a positive influence on their professional role. The strategy used by nurses who formulated nursing diagnoses involved the following steps in line with the clinical-decision model [19] a) investigating pre-encounter data, b) anticipating and controlling risks, c) being specific about the situation and the patient's subjective experience of his/her illness and d) generating hypotheses in the form of nursing diagnoses, presumably followed by the actions described in the nursing care plan.

In the current study we also assumed limited critical thinking in units that only used standardized care plans based on medical diagnoses or treatment, as the nurses applied preconceived nursing diagnoses to the patients. This is in line with a study by Lee [47], which found that nurses who utilized only standardized care plans focused on objective rather than subjective information when describing patients' health status.

Nurses who had an obvious nursing perspective used the assessment as a basis for alleviating suffering related to the patient's expressed problems, providing him/her with information and education and minimizing the risks associated with the hospital stay.

In contrast, nurses who mainly had a medical perspective did not discuss nursing risks with the patients. The observations and interviews revealed that none of the nurses who mainly had a medical perspective addressed the risk of e.g. pressure ulcers, falls or malnutrition. In these interviews, the patients' experiences were seldom in focus unless there were objective signs and measurable markers that indicated a medical reason for admission. One example was when a patient's subjective description and interpretation of her chest pain was disregarded when no objective findings or markers indicated vascular spasm. This can be compared with Jerlock's et al. [48] study, which revealed that patients who sought acute medical attention due to chest pain were assured that they were healthy, not in need of any treatment and told to go home. The focus of all the nurses in the study, irrespective of whether a medical or a nursing perspective was used, was the patients' physical and social needs. It is possible that the patients' emotional and cultural needs were neglected.

\section{CONCLUSIONS}

This study generated a core category indicating that the main concern of all nurses was to obtain a foundation for nursing care in their admission interview with the patient. This foundation was based on four strategies; building pre- understanding, creating a caring environment, collecting information on symptoms and signs and, finally, performing an analysis from different perspectives. This means that the aim of all nurses was to provide good care but that their perspective in the analysis of the assessed information differed. Nurses who had adopted a nursing perspective used critical thinking in their assessment and decision-making process in order to arrive at a nursing diagnosis. In contrast, nurses with a medical perspective did not use critical thinking to provide nursing care, as they did not intend to formulate nursing diagnoses. Instead, they simply entered data purely for the record. The focus of the admission interview for all nurses, irrespective of whether a nursing or a medical perspective was used, was the patient's physical and social needs.

\section{RECOMMENDATIONS FOR PRACTICE AND RESEARCH}

The result of this study indicates that, in order to provide high quality nursing care, nurses need more knowledge about critical thinking and the nursing process. Before they can adopt critical thinking, nurses need education pertaining to the nursing process and critical thinking, which they can acquire by means of case studies or, ideally, real world clinical situations. Such education is to some extent included in the theoretical part of the mandatory nursing education program curricula. However, in order to promote and ensure skillful use of all steps of the nursing process, it must be employed in a clinical setting. Implementation of a standardized language among experienced nurses must be prioritized along with theoretical education for nursing students. Further research is needed to explore the effects on patient well-being and satisfaction with care when nurses are aware of risks and perform skilful and proper assessment at an early stage by means of various measurement tools, resulting in a nursing diagnosis and evidence based interventions. Research is also needed to investigate what makes nurses in some units disregard legislation, which prevents them from taking a nursing perspective.

\section{REFERENCES}

[1] Ehrenberg A, Birgersson C. Nursing documentation of leg ulcers: adherence to clinical guidelines in a Swedish primary health care district. Scand J Caring Sci 2003; 17(3): 278-84.

[2] Törnvall E, Wahren LK, Wilhelmsson S. Impact of primary care management on nursing documentation. J Nurs Manag 2007; 15(6): $634-42$.

[3] Secrest JA, Norwood BR, DuMont PH. Physical assessment skills: a descriptive study of what is taught and what is practiced. J Prof Nurs 2005; 21(2): 114-8.

[4] Yura H, Walsh MB. The nursing process: assessing, planning, implementing, evaluating. $5^{\text {th }}$ ed. New York: Appleton \& Lange 1988.

[5] Thomas MD, Coombs RP. Nursing diagnosis: process and decision. In: La Monica EL, Ed. The nursing process: a humanistic approach. California: Addison Wesley. 1979; pp. 54-83.

[6] NANDA International. Nursing diagnosis: Definitions \& classifications 2003-2004. Philadelphia; NANDA International 2003.

[7] Fesler-Birch DM. Critical-thinking and patient outcomes: a review. Nurs Outlook 2005; 53(2): 59-65.

[8] Müller-Staub M, Lavin MA, Needham I, van Achterberg T Nursing diagnosis, interventions and outcomes - application and impact on nursing practice: systematic review. J Adv Nurs 2006; 56(5): 514-31.

[9] Müller-Staub M, Needham I, Odenbreit M, Lavin MA, van Achterberg T. Improved quality of nursing documentation: results of a nursing 
diagnoses, interventions, and outcomes implementation study. Int $\mathrm{J}$ Nurs Terminol Classif.ication 2007; 8(1): 5-17.

[10] Müller-Staub M, Needham I, Odenbreit M, Lavin MA, van Achterberg T. Implementing nursing diagnostics effectively: cluster randomized trial. J Adv Nurs 2008; 63(3): 291-301.

[11] Thoroddsen A, Ehnfors M. Putting policy into practice: pre- and posttests of implementing standardized languages for nursing documentation. J Clin Nurs 2007; 16(10): 1826-38.

[12] Urquhart C, Curell R, Grant MJ, Hardiker NR. Nursing record systems: effects of nursing practice and healthcare outcomes. Cochrane database Syst rev. 2009; 21(1): CD002099. Available from: http://mrw.interscience.wiley.com/cochrane/clsysrev/articles/CD 002099/frame.html [Cited May 26, 2009].

[13] Ehrenberg A, Ehnfors M. Patient problems, needs and nursing diagnoses in Swedish nursing home records. Nurs Diagn 1999; 10(2): 65-76.

[14] Björvell C, Wredling R, Thorell-Ekstrand I. Experiences of using the VIPS-model for nursing documentation: a focus group study. J Adv Nurs 2003; 43(4): 402-10.

[15] Hancock K, Chang E, Chenoweth L, Clarke M, Caroll A, Jeon YH. Nursing needs of acutely ill older people. J Adv Nurs 2003; 44(5): 507-16.

[16] Florin J, Ehrenberg A, Ehnfors M. Patients' and nurses' perceptions of nursing problems in an acute care setting. $\mathrm{J} \mathrm{Adv}$ Nurs 2005; 51(2): 140-9.

[17] Ehrenberg A, Ehnfors M. The accuracy of patient records in Swedish nursing homes: congruence of record content and nurses' and patients' descriptions. Scand J Caring Sci 2001; 15(4): 303-10.

[18] Tanner CA. Thinking like a nurse: a research-based model of clinical judgement in nursing. J Nurs Educ 2006; 45(6): 204-11.

[19] Banning M. A review of clinical decision making: models and current research. J Clin Nurs 2008; 17(2): 187-95.

[20] Lee J, Alfred CM, Phillips D. Diagnostic practise in nursing: a critical review of the literature. Nurs Health Sci 2006; 8(1): 57-65.

[21] Lunney M. Critical thinking and accuracy of nursing diagnosis. Int J Nurs Terminol Classification 2003; 14(3): 96-107.

[22] Lunney M. Current knowledge related to intelligence and thinking with implications for the development and use of case studies. Int $\mathrm{J}$ Nurs Terminol Classification 2008; 19(4): 158-62.

[23] Hedberg B, Sätterlund Larsson U. Observations, confirmations and strategies - useful tools in the decision-making process for nurses in practice? J Clin Nurs 2003; 12(2): 215-22.

[24] Ehrenberg A, Ehnfors M, Thorell-Ekstrand I. Nursing documentation in patient records: experience of the use of the VIPS-model. J Adv Nurs 1996; 24(4): 853-67.

[25] Gordon M. Nursing diagnosis: process and application. New York: Mc Graw - Hill Book co., 1982.

[26] Carnevali D. Diagnostic reasoning in nursing. Philadelphia: Lippincott 1984.

[27] Glaser B, Strauss A. The discovery of grounded theory. Strategies for qualitative research. Chicago: Aldine Publishing Company 1967.

[28] Hallberg L. The "core category" of grounded theory: making constant comparisons. Int J Qual Stud Health Well-being 2006; 1(3): 141-8

[29] Bryant A, Charmaz, K, Eds. The SAGE handbook of Grounded Theory. London: SAGE publications Ltd. Editorial 2007.
[30] Stern PN. On solid ground: essential properties for growing grounded theory. In: Bryant A, Charmaz, K, Eds. The SAGE handbook of grounded theory. London: SAGE publications Ltd. 2007; pp. 114-26.

[31] Charmaz K. Constructing grounded theory: a practical guide through qualitative analysis. London: Sage publications Ltd. 2006.

[32] Hildebrant M. Mediating structure in interaction in grounded theory. In: Bryant A, Charmaz, K, Eds. The SAGE handbook of grounded theory. London: SAGE publications Ltd. 2007; pp. 53964.

[33] Benner P. From novice to expert. Excellence and power in clinical nursing practice. California: Addison-Wesley publishing company 1984.

[34] Guigoz Y, Vellas B, Garry PJ. Assessing the nutritional status of the elderly: the mini nutritional assessment as part of the geriatric evaluation. Nutr Rev 1996; 54(1): 59-65

[35] Gadzik J. "How Much Should I Weigh?" - Quetelet's Equation, upper weight limits and BMI prime. Conn Med 2006; 70(2): 81-8.

[36] Perry L. Screening swallowing function of patients with acute stroke. Part one: identification, implementation and initial evaluation of a screening tool for use by nurses. J Clin Nurs 2001; 10(4): 463-73.

[37] Katz S, Ford AB, Moskowitz RW, Jackson BA, Jaffe MW. Studies of illness in the aged: the index of ADL: a standardized measure of biological and psycho-social function. JAMA 1963; 185: 914-9.

[38] Ek AC, Unosson M, Bjurulf P. The modified Norton scale and the nutritional state. Scand J Caring Sci 1989; 3(4): 183-7.

[39] Williams A, Davies H, Chadury Y. Simple pain rating scales hide complex idiosyncratic meanings. Pain 2000; 85(3): 457-63.

[40] Rosendahl E. Fall prediction and a high-intensity functional exercise programme to improve physical functions and to prevent falls among older people living in residential care facilities. Medical dissertations, Umeå University, Community Medicine and Rehabilitation 2006. Available from: http://urn.kb.se/resolve?urn= urn:nbn:se:umu:diva-756 [Cited Aug 6, 2009]

[41] Fredriksson L, Eriksson K. The ethics of the caring conversation. Nurs Ethics 2003; 10(2): 138-48.

[42] Encyclopedia Britannica. Human disease 2007. from encyclopedia Britannica online. Available from: http://search.eb.com/eb/article63219 [Cited 19 Sep 2007].

[43] Schmieding NJ. Ida Jean Orlando (Pelletier): nursing process theory. In: Tomey AM, Alligod MR, Eds. Nursing theorists and their work. Missouri: Mosby Elsevier 2006; pp. 431-51.

[44] Pesut DJ. The art science and complexity of clinical reasoning. In: Oud N, Ed. In: Acendio 2007, 6th European conference of acendio. Amsterdam: Oud Consultancy 2007; pp. 33-7.

[45] Benner R, Benner P. Stories from the front line. Healthc Forum J 1991; 34(4): 69-74.

[46] Axelsson L, Björvell C, Mattiasson A-C, Randers I. Swedish registered nurses' incentive to use nursing diagnosis in clinical practice. J Clin Nurs 2006; 15(8): 936-45.

[47] Lee T. Nursing diagnosis: factors affecting their use in charting standardized care plans. J Clin Nurs 2005; 14(5): 640-7.

[48] Jerlock M, Gaston-Johansson F, Danielsson E. Living with unexplained chest pain. J Clin Nurs 2005; 14(8): 956-64. 